\title{
PELAKSANAAN PROGRAM JALAN LAIN MENUJU MANDIRI DAN SEJAHTERA DI WILAYAH KOTA BATU
}

\section{Cahyo Sasmito}

Public Administration Study Program, Faculty of Social and Political Science, University of Tribhuwana Tunggadewi Malang 2019. Email:cahyosasmito1970@gmail.com

Ertien Rining Nawangsari,

Public Administration Study Program, Faculty of Social and Political Science, University of Tribhuwana Tunggadewi Malang 2019. Email:cahyosasmito1970@gmail.com

\begin{abstract}
Abstrak
Penelitian ini dilatar belakangi permasalahan kemiskinan, khususnya yang dialami kepala rumah tangga perempuan, serta adanya kebijakan pemerintah yang berbentuk Program Jalan Lain Menuju Mandiri Dan Sejahtera yang merupakan produk pemerintah pusat, dimana dalam pelaksanaannya melibatkan Pemerintah Provinsi Jawa Timur, Kota Batu dan Desa Pendem. Hal ini merupakan wujud komitmen pemerintah pusat untuk menjalankan program berkelanjutan dengan sasaran rakyat miskin khususnya Kepala Rumah Tangga Perempuan. Penelitian ini menggunakan metode kualitatif, Teknik pengumpulan data menggunakan: observasi, wawancara dan dokumentasi, dengan teknik penentuan sample mengunakan purposive sampling. Analisis data menggunakan: reduksi data, penyajian data dan penarikan kesimpulan. Serta keabsahan data menggunakan triangulasi. Hasil penelitian ini menunjukkan, secara umum Program-Jalin Matra mampu mengurangi kemiskinan di wilayah Kota Batu. Hal ini dibuktikan dengan adanya alokasi anggaran sebesar dua setengah juta pertahun untuk setiap kepala rumah tangga perempuan, serta ditunjang dengan tim pendamping yang memfasilitasi sarana dan prasarana yang dibutuhkan oleh Kepala Rumah Tangga Perempuan sesuai dengan bidang usaha yang ditekuninya. Tim pendamping akan membantu mengarahkan kepala rumah tangga perempuan sebagai sasaran program ini untuk mengembangkan usaha yang dimilikinya sehingga mampu memberdayakan kepala rumah tangga perempuan sebagai sasaran program tersebut mencapai tarap kehidupan yang mandiri dan sejahtera.
\end{abstract}

Kata Kunci: Kemiskinan, sasaran program, Mandiri dan Sejahtera

\begin{abstract}
This research is motivated by the problem of poverty, especially experienced by some womens as a head of household, as well as the existence of central government policies in form of Jalin-Matra (Jalan Lain Menuju Mandiri dan Sejahtera) Program, which in their implementation involved the Provincial Government of East Java, Batu City and Pendem Village. This is the central government's manifestation of the commitment to carry out sustainable programs that targeted to the poor womens as a head of the household. This study uses qualitative methods, data collection techniques using: observation, interviews and observation, with sample selection techniques using purposive sampling. Data analysis uses: data reduction, data presentation and conclusion conclusion. Then the validity of the data using triangulation. The results of this study indicate that, generally, the Jalin-Matra Program is able to reduce poverty in the area of Batu City. This is evidenced by the existence of a budget allocation ammounts two and a half million per year for each women as a head of household, and also supported by facilitators team who facilitate the facilities and infrastructure needed by the women as a head of household in accordance with the line of their business. The team will help to direct the women as a head of household as the target of this program to develop a business that facilitated by empowering them to achieve an independent and prosperous life plan.
\end{abstract}

Keywords: Poverty, target programs, Independent and Prosperous.

\section{PENDAHULUAN}

Kemiskinan merupakan permasalahan yang dihadapi oleh semua negara, terlebih dihadapi oleh negara sedang berkembang dengan berbagai daya dan upaya untuk menyelesaikan kemiskinan ini. Di Negara Indonesia persoalan kemiskinan ini dianggap sebagai persoalan serius yang masuk dalam agenda pemerintah untuk mengurangi dan menyelesaikannya dari waktu ke waktu. Pemerintah sebelumnya membuat kebijakan seperti Program Keluarga Harapan yang diperuntukan guna mengatasi permasalahan kemiskinan, selanjutnya pemerintah juga membuat kebijakan yang bernama Program Jalan Lain Menuju Mandiri Dan Sejahtera (Program-Jalin Matra) yang sasarannya diarahkan pada keluarga miskin dengan prioritas kepala rumah tangganya adalah seorang perempuan. Program-Jalin Matra ini juga bertujuan untuk mengurangi angka kemiskinan, dibeberapa daerah di wilayah Indonesia, salah satu contoh real program ini dilaksanakan di Desa Pendem Kecamatan Junrejo Kota Batu Provinsi Jawa Timur. Pemerintah berusaha untuk memastikan bahwa 
program ini dapat dilaksanan dengan efektif diberbagai daerah. Program Jalin Matra sasarannya adalah kepala keluarga perempuan, hal ini dilatarbelakangi karena selama ini peran perempuan lebih sedikit dibandingkan dengan peran laki-laki terkait dengan akses di sektor publik. Program Jalan Lain Menuju Mandiri Dan Sejahtera ini menunjukkan perlunya keterlibatan perempuan dalam menyelesaikan persoalan kemiskinan, yang merupakan persoalan Negara khususnya kemiskinan dimana peran serta secara aktif dari kepala rumah tangga perempuan hal ini ini sesuai dengan Peraturan Menteri Dalam Negeri Nomor 15 Tahun 2008 Tentang Pedomana Umum Pelaksana Pengarusutamaan Gender dalam Pembangunan di Daerah. Dari aturan tersebut .

Pemerintah Provinsi Jawa Timur memiliki komitmen dalam hal Pengharusutamaan Gender, hal ini sesuai dengan Program Jalin Matra yang sasaran programnya pada kepala rumah tangga perempuan, komitmen ini nampak dengan dimasukkannya Pengharusutamaan Gender kedalam kebijakan Rencana Strategis Provinsi Jawa Timur dalam sebuah Peraturan Daerah Provinsi Jawa Timur Nomor 3 Tahun 2014 tentang Rencana Pembangunan Jangka Menengah Daerah (RPJMD) Tahun 2014-2019. Selanjutnya didukung dengan dikeluarkannya Peraturan Gubernur Jawa Timur Nomor 13 Tahun 2016 Tentang Pedoman Umum Program Jalin Matra. Selanjutnya terkait dengan Program Jalan Lain Menuju Mandiri Dan Sejahtera (Program-Jalin Matra), Pemerintah Provinsi Jawa Timur menerbitkan Peraturan Gubernur Tentang Pedoman Umum Program Jalan Lain Menuju Mandiri Dan Sejahtera (JALIN MATRA) yang dilaksanakan diseluruh wilayah Provinsi Jawa Timur, termasuk Kota Batu yang merupakan salah satu kota di wilayah Jawa Timur yang melaksanakan Program-Jalin Matra tersebut.

Program-Jalin Matra ini pada dasarnya merupakan program pemerintah pemerintah pusat yang berorientasi pada pemberdayaan kaum perempuan, oleh karenanya mulai dari perencanaan program, pelaksanaan program dan anggaran, dimana secara spesifik pelaksanaan program ini dibebankan kepada pemerintah daerah provinsi yang bekerjasama dengan pemerintah daerah dengan tujuan membantu persoalan perempuan khususnya kepala keluarga perempuan dalam menghadapi persoalan kemiskinan yang dihadapi dalam rumah tangganya. Program Jalin Matra di Desa Pendem Kecamatan Junrejo Kota Batu dilaksanakan dalam rangka pemberdayaan perempuan di desanya untuk menanggulangi masalah kemisikinan di keluarga yang bersangkutan. Program ini juga bertujuan agar kepala rumah tangga perempuan yang menjadi peserta program ini lebih mudah untuk mencapai tarap hidup mandiri dan sejahtera dalam rumah tanggannya tersebut. Pelaksanaan program Jalan Lain Menuju Mandiri Dan Sejahtera, sesuai dengan teori George Edwards III (1980); dalam mengimplementasikan kebijakan publik, hendaknya mempertimbangkan 4 (empat) faktor, yakni: Komunikasi, Sumber Daya, Disposisi, Struktur Birokrasi (Kadji Y, 2016:63)

\section{METODOLOGI}

Metode penelitian ini dengan menggunakan pendekatan deskriptif kualitatif (Moleong, 2014), Sumber Data: data primer; dari hasil wawancara yang mengacu pada pedoman wawancara yang ditetapkan, dan observasi; serta data sekunder; dari informasi pihak kedua, serta dokumentasi diperoleh dari pemerintahan: desa, kota dan provinsi. Instrumen penelitian: peneliti sendiri, teknik pemilihan sampel dengan cara Purposive sampling, teknik pengumpulan data: wawancara, pengamatan, dan dokumentasi. Teknik Keabsahan: Triangulasi data. Teknik Analisis Data dengan menggunakan Model interaktif Miles dan Huberman (Soegiono, 2017) yang meliputi: Reduksi data (merangkum/memilih hal-hal yang dianggap pokok), Penyajian data (berbentuk: uraian singkat; hubungan antar kategori; bagan; flowchart; dan lain sebagainya), penarikan kesimpulan/verifikasi (mendiskripsikan atau menggambarkan suatu objek penelitian secara jelas).

\section{HASIL DAN PEMBAHASAN}

Pelaksanaan Program Jalan Lain Menuju Mandiri Dan Sejahtera Di Wilayah Kota Batu: dengan tujuan untuk menggurangi angka kemiskinan dengan sasaran Kepala Rumah Tangga Perempuan:

Komunikasi: sosialisasi dilakukan kepada masyarakat desa dengan tujuan agar Kepala Rumah Tangga Perempuan sebagai sasaran Pogram-Jalin Matra mampu memahami arah dan tujuan dari program tersebut, dan bisa menghindari hal negatif yang tidak diinginkan. Komunikasi: Program Jalin Matra bertujuan untuk menanggulangi kemiskinan di Desa, serta untuk membantu mengembangkan usaha yang dimiliki oleh peserta program-Jalin Matra sebagai sasaran program untuk meningkatkan taraf hidupnya menjadi mandiri dan sejahtera.

Komunikasi: memberikan bantuan kepada Kepala Rumah Tangga Perempuan sebagai peserta program-Jalin Matra berupa alat-alat perlengkapan untuk membuat usaha, dan mengembangkan usaha seperti: gas LPJ, dandang pengukus, beras dan lain sebagainya, yang berupa bantuan dalam bentuk 
barang kepada setiap Kepala Rumah Tangga Perempuan sebesar dua juta lima ratus ribu rupiah. Komunikasi dan interaksi antara tim pendamping dengan Kepala Rumah Tangga Perempuan sebagai peserta program-Jalin Matra, dalam hal menyampaikan pesan yang jelas, terarah, terencana, serta tepat sasaran terkait tujuan program-Jalin Matra untuk meningkatkan taraf hidup peserta program menjadi mandiri dan sejahtera.

Sumberdaya: Program-Jalin Matra dilaksanakan oleh Pemerintah Desa Pendem dan Aparaturnya serta dibantu oleh tim pendamping kepada Kepala Rumah Tangga Perempuan sebagai peserta program-Jalin Matra memberikan modal dua juta lima ratus ribu rupiah untuk mengembangkan usaha sasaran program dengan tujuan untuk mencapai tarap hidup mandiri dan sejahtera.

Sumberdaya: Pendayagunaan aparatur Pemerintah Desa mengkoordinasikan pelaksanaan program-Jalin Matra oleh Aparatur pemerintah yang dibantu oleh tim pendamping diberikan kepada Kepala Rumah Tangga Perempuan sebagai peserta program-Jalin Matra untuk meningkatkan taraf hidup peserta program menjadi mandiri dan sejahtera. Sumberdaya: untuk melakukan pemantauan dan evaluasi dari kinerja penyelenggara pelayanan publik khususnya pelaksana penyelenggara Program Jalin Matra agar sesuai prosedur dan tepat sasaran, dalam pentuan Kepala Rumah Tangga sasaran disini sesuai prosedur sudah tepat sasaran.

Sumberdaya: Program-Jalin Matra dilaksanakan oleh Pemerintah Desa Pendem dan Aparaturnya serta dibantu oleh tim pendamping kepada Kepala Rumah Tangga Perempuan sebagai peserta program-Jalin Matra dilaksanakan dengan tujuan untuk meningkatkan efisiensi dan efektivitas kegiatan untuk meningkatkan taraf hidup peserta program menjadi mandiri dan sejahtera. Sumberdaya: Program-Jalin Matra dilaksanakan oleh Pemerintah Desa Pendem dan Aparaturnya serta dibantu oleh tim pendamping pihak yang berwenang, serta bertangungjawab atas proses pelaksanaan program Jalin Matra yang diberikan kepada Kepala Rumah Tangga Perempuan sebagai peserta program-Jalin Matra.

Disposisi: karakter aparat Desa Pendem, pendamping, dan Kepala Rumah Tangga Perempuan sebagai peserta program-Jalin Matra telah berhasil melaksanakan program ini secara baik sesuai dengan tujuan yang ditetapkan oleh pemerintahan pusat maupun pemerintahan provinsi dalam hal meningkatkan efisiensi dan efektivitas, kegiatan tersebut untuk meningkatkan taraf hidup peserta program ini menjadi mandiri dan sejahtera.
Struktur Birokrasi: struktur birokrasi yang handal, baik di pemerintahan pusat, pemerintahan provinsi, dan pemerintah kota beserta pemerintahan desa pendem menunjukkan hasil yang baik, sesuai prosedur dan tepat sasaran untuk meningkatkan taraf hidup, peserta program tersebut menjadi mandiri dan sejahtera

Faktor Pendukung: Pelaksanaan Program Jalan Lain Menuju Mandiri Dan Sejahtera Di Wilayah Kota Batu: dengan tujuan untuk menggurangi angka kemiskinan dengan sasaran Kepala Rumah Tangga Perempuan

Faktor pendukung dalam Proses Pelaksanaan Program Jalin Matra seperti, adanya partisipasi dari masyarakat dan dilengkapi dengan adanya sarana dan prasarana yang difasilitasi oleh aparatur pemerintah dan dibantu oleh tim pendamping yang bertangungjawab atas proses pelaksanaan program Jalin Matra yang diberikan kepada Kepala Rumah Tangga Perempuan sebagai peserta program-Jalin Matra.

Faktor pendukung dalam Proses Pelaksanaan Program Jalin Matra; Adanya kerja sama antara Tim Pedamping dan sasaran Program Jalin Matra, dalam pelaksanaanya dilapangan dibantu oleh aparat pemerintah Desa secara baik kerjasama ini dilaksanakan bakan dengan antusias dan semangat dalam memberikan bantuan kepada Kepala Rumah Tangga Perempuan sebagai sasaran program-Jalin Matra tersebut.

Faktor pendukung dalam Proses Pelaksanaan Program Jalin Matra; Adanya alokasi dana atau bantuan berupa uang tunai sebesar dua juta lima ratus ribu rupiah dengan tujuan untuk mengembangkan usaha yang dimiliki oleh kepala rumah tangga perempuan sebagai sasaran program untuk mewujudkan tarap hidup yang mandiri dan sejahtera. Adanya struktur birokrasi yang mendukung dari awal adanya proses perekrutan Tim Pendamping Program Jalin Matra sesuai prosedur yang sudah ditetapkan sehingga tim pendamping ini dapat melaksanakan tugas, fungsi secara baik, dan tepat sasaran. Faktor pendukung selanjutnya dalam Proses Pelaksanaan Program Jalin Matra; kepada Kepala Rumah Tangga Perempuan sebagai peserta program-Jalin Matra secara lancer, hal ini ditunjang oleh struktur birokrasi pemerintah daerah Kota Batu, Kecamatan Junrejo, Desa pendem dengan didukung oleh perangkat desa: rukun tetangga, rukun warga, kepala dusun.

Faktor Penghambat: Pelaksanaan Program Jalan Lain Menuju Mandiri Dan Sejahtera Di Wilayah Kota Batu: dengan tujuan untuk 
menggurangi angka kemiskinan dengan sasaran Kepala Rumah Tangga Perempuan:

Faktor penghambat: proses pelaksanaan Program Jalin Matra adalah data kependudukan Kepala Rumah Tangga Perempuan sebagai peserta program-Jalin Matra, yang menjadi sasaran terdapat identitas yang tidak lengkap sebagaimana yang dikehendaki sebagaimana prosedur yang telah ditetapkan.

Faktor penghambat: proses pelaksanaan Program Jalin Matra kepada Kepala Rumah Tangga Perempuan sebagai peserta program-Jalin Matra, dimana Kualitas Sumber Daya Manusia (SDM) peserta program masih kurang, sehingga untuk menanggulangi kemiskinan melalui Program Jalin Matra tidak dapat dicapai dengan baik.

Faktor penghambat: proses pelaksanaan Program Jalin Matra kepada Kepala Rumah Tangga Perempuan sebagai peserta program-Jalin Matra ini, tidak ada pengawasan yang efektif. Sehingga dalam pelaksanaan Program Jalin Matra yang di laksanakan oleh pemerintah Desa belum ada bentuk pengawasan yang baik dari pihak terkait yang berwenang masih kurang, sehingga menghambat keberhasilan program Jalin Matra yang dijalankan tersebut.

\section{PENUTUP}

\section{Simpulan}

1. Pelaksanaan Program Jalan Lain Menuju Mandiri Dan Sejahtera Di Wilayah Kota Batu: Komunikasi: sosialisasi kepada masyarakat desa untuk menentukan nama sasaran program: Kepala Rumah Tangga Perempuan sebagai sasaran Pogram-Jalin Matra, mampu memahami arah dan tujuan dari program yakni menanggulangi kemiskinan, dengan cara mengembangkan usahanya sehingga taraf hidupnya meningkat menjadi mandiri dan sejahtera. Sumberdaya: Program-Jalin Matra ini dilaksanakan oleh Aparatur Pemerintah Desa, tim pendamping, dan Kepala Rumah Tangga Perempuan sebagai sasaran program-Jalin Matra untuk meningkatkan taraf hidup peserta program menjadi mandiri dan sejahtera. Disposisi: karakter atau watak aparat Desa Pendem, pendamping, dan Kepala Rumah Tangga Perempuan sebagai peserta program-Jalin Matra telah berhasil melaksanakan program ini secara baik. Struktur Birokrasi: struktur birokrasi yang handal mulai dari pemerintahan pusat, sampai pemerintahan desa, melaksanakan tugas, menentukan peserta program mendukung terwujudnya tujuan yang ditetapkan yakni meningkatkan taraf hidup peserta program menjadi mandiri dan sejahtera.

2. Faktor Pendukung dan Penghambat Pelaksanaan Program Jalan Lain Menuju Mandiri Dan Sejahtera Di Wilayah Kota Batu. Faktor pendukung: adanya partisipasi masyarakat dan kerjasama yang baik dengan pendamping, serta dukungan sarana dan prasarana dari pemerintah pusat sampai desa, berhasil meningkatkan taraf hidup peserta program menjadi mandiri dan sejahtera. Faktor penghambat: masih ada data kependudukan Kepala Rumah Tangga Perempuan sebagai peserta program-Jalin Matra, yang identitasnya yang tidak lengkap. Kualitas Sumber Daya Manusia peserta program masih kurang. Kurangnya pengawasan yang efektif.

\section{DAFTAR PUSTAKA}

Moleong, J. Lexi.2014. Metodologi Penelitian Kualitatif: PT Remaja Rosdakarya Bandung.

Sugiyono. 2017. Metode Penelitian Kualitatif, Kualitatif Dan R\&D: Alfabeta CV Bandung.

Kadji, Y. 2016. Formulasi dan Implementasi Kebijakan Publik: Kepemimpinan dan Perilaku Birokrasi Dalam Fakta Realitas.UNG Press Gorontalo.

Peraturan Daerah Provinsi Jawa Timur Nomor 3 Tahun 2014 tentang Rencana Pembangunan Jangka Menengah Daerah (RPJMD) Tahun 2014-2019.

Peraturan Gubernur Jawa Timur Nomor 13 Tahun 2016 Tentang Pedoman Umum Program Jalin Matra.

Peraturan Mentri Dalam Negeri Nomor 15 Tahun 2008 Tentang Pedomana Umum Pelaksana Pengarusutamaan Gender dalam Pembangunan di Daerah. 